Jurnal Care Vol .5, No.3,Tahun 2017

\title{
PENGARUH KOMUNIKASI TERAPEUTIK DAN SENAM HAMIL TERHADAP PROSES PERSALINAN KALA I,II,III,IV
}

\author{
Titin Sutriyani ${ }^{1)}$ Yusnita Julyarni Akri ${ }^{2)}$ \\ D4 Kebidanan Universitas Tribhuwana Tunggadewi \\ e-mail: titinsutriyani@gmail.com
}

\begin{abstract}
Partus or maternity is an opening and thinning process of pregnant woman's cervix for pushing fetus down to passage through normal pregnancy time (37-42 weeks) in spontaneous labour by back head presentation which lasts about 14 $1 / 2$ hours under no complication to the mother and the baby. There are central factors in a maternity process such as a) power (pushing power to let the baby out), b) passage (labour passage), and c) passanger (fetus). By these considerations mother who will have birth must be given theraupetic communication and pregnancy exercises. The purpose of this research is to know the influence of therapeutic communication for labour/maternity process. This research held in Ny.Maria, Amd.Keb, S.ST Maternity Clinic at Bratan Timur Street No H7A10 in Malang, East Java. It employed two types of treatments which consisted of (1) pregnant mother treated to do pregnancy exercises (2) partus mother treated by therapeutic communication. The following step then to analyze the data by $T$ Test approach. From the result of this research is found that therapeutic communication and pregnancy exercises has strong influences to blood pressure (systole, diastole, pulse, body temperature, respiration also bleeding in first, second, third, and fourth stages of maternity process). The comparison between group treated by therapeutic communication and group treated by pregnancy exercises reached a conclution that theraupeutic communication was more dominant to help labour process (partus) at the first, second, third, and fourth stages than pregnancy exercises.
\end{abstract}

Keywords: therapeutic communication, pregnancy exercises, maternity process.

\begin{abstract}
ABSTRAK
Persalinan merupakan proses fisiologis, bila proses persalinan tidak mendapatkan informasi dengan jelas, maka proeses fisiologis dapat menjadi patologis. Diperlukan adanya komunikasi terapeutik guna membantu pasien dalam memperjelas dan mengurangi beban perasaan dan pikiran. Senam hamil membantu pemperlancar persalinan. Tujuan dari penelitian ini adalah untuk mengetahui pengaruh komunikasi terapeutik dan senam hamil terhadap proses persalinan. Penelitian ini merupakan penelitian eksperiment, yang dilaksanakan di BPM Ny. Maria, Amd.Keb,S.ST. Populasi adalah ibu hamil yang mengikuti senam hamil dan melahirkan di BPM Bidan Maria, dengan jumlah sampel 50 orang yang terbagi menjadi 2 kelompok perlakuan.Kelompok 1 diberi perlakuan senam hamil dan kelompok 2 diberi komunikasi terapeutik. Instrumen yang digunakan adalah lembar observasi. Analisis yang digunakan adalah pendekatan Uji T Test. Hasil penelitian menunjukkan bahwa komunikasi teraupeutik dan senam hamil sangat berpengaruh terhadap tekanan darah systole, diastole, nadi, suhu, pernafasan dan perdarahan pada kala I,II,III, dan IV.Analisa statistic
\end{abstract}


Jurnal Care Vol .5, No.3,Tahun 2017

menunjukkan bahwa komunikasi terapeutik lebih dominan terhadap proses persalinan kala I,II,III, dan IV dibandingkan dengan senam hamil.

Kunci : Komunikasi Terapeutik, Proses Persalinan, Senam Hamil

\section{PENDAHULUAN}

Persalinan merupakan proses fisiologis, bila proses persalinan tidak mendapatkan informasi dengan jelas, maka proses fisiologis dapat menjadi patologis oleh karena itu ibu yang akan bersalin perlu mendapatkan informasi dengan jelas tentang keadaan ibu itu sendiri maupun bayinya, maka dari itu komunikasi terapeutik dan senam hamil sangat diperlukan.. Komunikasi terapeutik bermanfaat untuk membantu pasien dalam memperjelas dan mengurangi beban perasaan dan pikiran serta dapat mengambil tindakan untuk mengubah situasi yang ada agar pasien percaya pada hal yang diperlukan, mengurangi keraguan, membantu dalam hal mengambil tindakan yang efektif dan mempertahankan kekuatan egonya dan mempengaruhi orang lain, lingkungan fisik dan dirinya sendiri ((Mukhripah (2008)

Senam hamil merupakan suatu proses dalam persiapan persalinan, adapun manfaat senam hamil antara lain memperbaiki sirkulasi darah, menggurangi bengkak terutama kaki, Meningkatkan keseimbangan otot-otot, mengurangi kejang kaki/kram, menguatkan otot-otot perut, memperbaiki posisi janin (Hani dkk, 2010).Proses persalinan dibagi menjadi 4 kala yakni kala 1 (kala pembukaan). Kala I dimulai sejak terjadinya kontraksi uterus dan pembukaan serviks hingga mencapai pembukaan lengkap $(10 \mathrm{~cm})$. Kala satu dibagi menjadi dua yaitu fase laten dan fase aktif. Fase laten yaitu dimulai sejak awal berkontraksi yang menyebakan penipisan dan pembukaan serviks secara bertahap, berlangsung hingga serviks membuka kurang dari $4 \mathrm{~cm}$, dan pada umumnya fase laten berlangsung selama 8 jam. Sedangkan fase aktif persalinan yang meliputi frekuensi dan lama kontraksi uterus umumnya meningkat (kontraksi dianggap adekuat/memadai jika terjadi tiga kali atau ebih dalam 10 menit dan berlangsung selam 40 detik atau lebih), serviks membuka dari 4-10 cm, biasanya dengan kecepatan $1 \mathrm{~cm}$ atau lebih per jam hingga pembukaan lengkap $(10 \mathrm{~cm})$, terjadi penurunan bagian terbawah janin (Sujiatini, 2010).

Kala II Persalinan adalah dimulainya sejak pembukaan lengkap sampai lahirnya bayi. Gejala dan tanda kala dua adalah ibu merasa 
Jurnal Care Vol .5, No.3,Tahun 2017

ingin meneran bersamaan dengan terjadinya kontraksi, ibu merasakan adanya peningkatan tekanan pada rektum dan atau vaginanya, perineum menonjol, vulva-vagina dan sfingter ani membuka, dan meningkatnya pengeluaran lendir bercampur darah. Tanda pasti kala II ditentukan melalui periksa dalam, yaitu : Pembukaan serviks telah lengkap dan terlihatnya bagian kepala bayi introitus vagina.

Menurut Depkes (2008) disampaikan bahwa Kala III dimulai setelah lahirnya bayi dan berakhir lahirnya plasenta dan selaput ketuban. Setelah bayi lahir kontraksi rahim beristirahat sebentar. Uterus teraba keras dengan fundus uteri setinggi pusat, berisi plasenta yang menjadi tebal dua kali sebelumnya. Beberapa saat kemudian datang his pelepasan dan pengeluaran uri. Dalam waktu 5-15 menit seluruh plasenta terlepas didorong kedalam vagina dan akan lahir spontan atau dengan sedikit dorongam diatas simpisis atau fundus uteri seluruh proses biasanya berlangsung 5-30 menit setelah bayi lahir. Pengeluaran plasenta disertai dengan pengeluaran darah kira-kira 100-200cc.

Kala IV adalah kala pengawasan 1 jam setelah bayi dan uri lahir untuk mengamati keadaan ibu terutama terhadap bahaya perdaahan postpartum. Asuhan ibu bersalin pada kala IV terdiri dari evaluasi kontinue terhadap setiap temuan atau perkembangan ssignifikan selama periode antepartum dan intrapartum, evaluasi perubahan fisiologis dan anatomis puerperium, evaluasi tanda-tanda vital wanita dan tanda, gejala,serta perubahan fisik, evaluasi respon ibu dan ayah terhadap bayi mereka dan persiapan mereka untuk pengasuhan, evaluasi perubahan perilaku wanita dan respon psikologis terhadap kelahirannya, penapisan kontinue terhadap tanda dan gejala komplikasi obstetri atau medis (Hidayat,Sujiatini ， 2010).Yang diharapkan oleh seorang ibu dalam proses persalinan adalah proses persalinan yang fisiologis. Oleh karena itu diperlukan adanya informasi tentang komunikasi terapeutik, manfaat dari senam hamil, proses persalinan kala I,II,III dan IV. Berdasarkan latar belakang tersebut diatas maka peneliti sangat tertarik untuk melakukan penelitian yang berjudul pengaruh komunikasi terapeutik dan senam hamil terhadap proses persalinan kala I,II,III,dan IV

\section{METODE PENELITIAN}

Penelitian ini merupakan penelitian eksperiment, yang dilaksanakan di BPM Ny. Maria, Amd.Keb,S.ST. Populasi adalah ibu hamil yang mengikuti senam hamil dan 
Jurnal Care Vol .5, No.3,Tahun 2017

melahirkan di BPM Bidan Maria, dengan jumlah sampel 50 orang yang terbagi menjadi 2 kelompok perlakuan.Kelompok 1 diberi perlakuan senam hamil dan kelompok 2 diberi komunikasi terapeutik. Instrumen yang digunakan adalah lembar observasi Analisa data menggunakan alat bantu komputer SPSS (Statistical Program for Social Science) for windows dengan uji $\mathrm{T}$ Test tidak berpasangan.

\section{HASIL}

Tabel 1. Hasil Pengujian Pengaruh Komunikasi Terapeutik dan Senam Hamil Terhadap Proses Persalinan Kala I,II,III, dan IV

\begin{tabular}{lcccccc}
\hline \multicolumn{1}{c}{ Variabel } & \multicolumn{2}{c}{ Mean } & \multicolumn{2}{c}{ Min \pm Maks } & Z & p-value \\
\cline { 2 - 6 } & $\begin{array}{c}\text { Senam } \\
\text { Hamil }\end{array}$ & $\begin{array}{c}\text { Kom. } \\
\text { Tera } \\
\text { peutik }\end{array}$ & $\begin{array}{c}\text { Senam } \\
\text { Hamil }\end{array}$ & $\begin{array}{c}\text { Kom. } \\
\text { Tera } \\
\text { peutik }\end{array}$ & & \\
\cline { 2 - 6 } $\begin{array}{l}\text { Tekanan darah } \\
\text { Sistole }\end{array}$ & 118,20 & 11,60 & $110 \pm 125$ & $100 \pm 120$ & $-3,264$ & 0,001 \\
\hline $\begin{array}{l}\text { Tekanan darah } \\
\text { Diastole }\end{array}$ & 78 & 71,16 & $70 \pm 85$ & $60 \pm 80$ & $-3,472$ & 0,001 \\
\hline Nadi & 88,28 & 84,96 & $87 \pm 89$ & $80 \pm 88$ & $-4,878$ & 0,000 \\
\hline $\begin{array}{l}\text { Suhu } \\
\text { Pernafasan }\end{array}$ & 36,6 & 36,5 & $36,4 \pm 37$ & $36,4 \pm 36,7$ & $-2,738$ & 0,006 \\
\hline DJJ & 19,32 & 18,56 & $17 \pm 21$ & $18 \pm 20$ & $-3,099$ & 0,002 \\
\hline $\begin{array}{l}\text { Lama } \\
\text { Persalinan }\end{array}$ & 139 & 136,2 & $130 \pm 145$ & $130 \pm 140$ & $-2,109$ & 0,035 \\
Kala I & 174 & 156 & $120 \pm 250$ & $120 \pm 180$ & $-2,278$ & 0,023 \\
\hline
\end{tabular}

Pada Tabel 1 diketahui tekanan sistole, diastole, nadi, suhu, pernafasan, DJJ dan lama persalinan kala I antara dua kelompok mempunyai $\mathrm{p}$ value $<0,005$ artinya terdapat pengaruh perubahan tekanan sistole, diastole, nadi, suhu, pernafasan, DJJ dan lama persalinan kala I antara kelompok perlakuan senam hamil dan kelompok komunikasi terapeutik. Pengaruh proses persalinan kala I yang paling dominan adalah pada kelompok komunikasi terapeutik dapat dilihat nilai mean semua variabelnya lebih kecil dibandingkan dengan senam hamil.

Tabel 2 diketahui bahwa tekanan sistole, diastole, nadi, suhu, pernafasan, dan lama persalinan kala II antara dua kelompok mempunyai $\mathrm{p}$-value $<0,005$ artinya terdapat pengaruh perubahan tekanan sistole, diastole, nadi, suhu, pernafasan, lama persalinan kala II antara kelompok perlakuan senam hamil dan 
Jurnal Care Vol .5, No.3,Tahun 2017

kelompok komunikasi terapeutik. Pengaruh proses persalinan kala II yang paling dominan adalah pada kelompok komunikasi terapeutik dapat dilihat nilai mean semua variabelnya lebih kecil dibandingkan dengan senam hamil.

Tabel 2. Hasil Pengujian Perubahan Tekanan Sistole,Diastole,Nadi,Suhu,Pernafasan,Lama Persalinan Kala II Pada Kelompok Perlakuan Senam Hamil dan Kelompok Komunikasi Terapeutik

\begin{tabular}{|c|c|c|c|c|c|c|}
\hline \multirow[t]{2}{*}{ Variabel } & \multicolumn{2}{|c|}{ Mean } & \multicolumn{2}{|c|}{ Min \pm Maks } & \multirow[t]{2}{*}{$\mathbf{Z}$} & \multirow[t]{2}{*}{ p-value } \\
\hline & $\begin{array}{l}\text { Senam } \\
\text { Hamil }\end{array}$ & $\begin{array}{c}\text { Kom. } \\
\text { Tera } \\
\text { peutik }\end{array}$ & $\begin{array}{l}\text { Senam } \\
\text { Hamil }\end{array}$ & $\begin{array}{l}\text { Kom. Tera } \\
\text { peutik }\end{array}$ & & \\
\hline $\begin{array}{l}\text { Tekanan darah } \\
\text { Sistole }\end{array}$ & 118,80 & 114,4 & $110 \pm 125$ & $100 \pm 120$ & $-2,854$ & 0,004 \\
\hline $\begin{array}{l}\text { Tekanan darah } \\
\text { Diastole }\end{array}$ & 85,88 & 83,28 & $80 \pm 87$ & $78 \pm 86$ & $-4,254$ & 0,000 \\
\hline Nadi & 82,92 & 81 & $80 \pm 84$ & $77 \pm 83$ & $-3,962$ & 0,000 \\
\hline Suhu & 36,8 & 36,7 & $36,6 \pm 37,5$ & $36,5 \pm 36,9$ & $-2,849$ & 0,004 \\
\hline Pernafasan & 18,4 & 17,6 & $16 \pm 20$ & $17 \pm 19$ & $-3,026$ & 0,002 \\
\hline $\begin{array}{l}\text { Lama Persalinan } \\
\text { KalaII }\end{array}$ & 60,6 & 50,8 & $50 \pm 70$ & $40 \pm 60$ & $-4,146$ & 0,000 \\
\hline
\end{tabular}

Berdasar Tabel 3 diketahui tekanan sistole, diastole, nadi, suhu, pernafasan, perdarahan dan lama persalinan kala III antara dua kelompok mempunyai $\mathrm{p}$ value $<0,005$ artinya terdapat pengaruh perubahan tekanan sistole, diastole, nadi, suhu, pernafasan, perdarahan dan lama persalinan kala III antara kelompok perlakuan senam hamil dan kelompok komunikasi terapeutik. Pengaruh proses persalinan kala III yang paling dominan adalah pada kelompok komunikasi terapeutik dapat dilihat nilai mean semua variabelnya lebih kecil dibandingkan dengan senam hamil. Tabel 4 diketahui bahwa tekanan sistole, diastole, nadi, suhu, pernafasan, perdarahan dan antara dua kelompok mempunyai $\mathrm{p}$ value $<0,005$ artinya terdapat pengaruh perubahan tekanan sistole, diastole, nadi, suhu, pernafasan, perdarahan antara kelompok perlakuan senam hamil dan kelompok komunikasi terapeutik. Pengaruh proses persalinan kala IV yang paling dominan adalah pada kelompok komunikasi terapeutik dapat dilihat nilai mean semua variabelnya lebih kecil dibandingkan dengan senam hamil.

Berdasarkan hasil penelitian dapat dilihat bahwa komunikasi terapeutik dan senam hamil sangat berpengaruh terhadap tekanan 
Jurnal Care Vol .5, No.3,Tahun 2017

darah systole, diastole, nadi, suhu, pernafasan dan perdarahan pada kala I,II,III,IV. Dari data diatas dapat dilihat bahwa kelompok komunikasi terapeutik nilai mean semua variabelnya lebih kecil dibandingkan dengan senam hamil. Dapat disimpulkan bahwa komunikasi terapeutik lebih berpengaruh terhadap proses persalinan kala I,II,III,IV dibandingkan dengan senam hamil.

Tabel 3. Hasil Pengujian Perubahan Tekanan Sistole,Diastole,Nadi,Suhu,Pernafasan,Lama Persalinan Kala III Pada Kelompok Perlakuan Senam Hamil dan Kelompok Komunikasi Terapeutik

\begin{tabular}{lcccccc}
\hline \multirow{1}{*}{ Variabel } & \multicolumn{2}{c}{ Mean } & \multicolumn{2}{c}{ Min \pm Maks } & Z & p-value \\
\cline { 2 - 6 } & $\begin{array}{l}\text { Senam } \\
\text { Hamil }\end{array}$ & $\begin{array}{c}\text { Kom. } \\
\text { Tera } \\
\text { peutik }\end{array}$ & $\begin{array}{c}\text { Senam } \\
\text { Hamil }\end{array}$ & $\begin{array}{c}\text { Kom. Tera } \\
\text { peutik }\end{array}$ & & \\
\hline $\begin{array}{l}\text { Tekanan darah } \\
\text { Sistole }\end{array}$ & 111,9 & 116,2 & $110 \pm 125$ & $110 \pm 120$ & $-2,109$ & 0,035 \\
\hline $\begin{array}{l}\text { Tekanan darah } \\
\text { Diastole }\end{array}$ & 76,8 & 71,2 & $70 \pm 85$ & $60 \pm 80$ & $-3,212$ & 0,001 \\
\hline Nadi & 86,8 & 84 & $80 \pm 89$ & $80 \pm 88$ & $-3,362$ & 0,001 \\
\hline Suhu & 36,8 & 36,6 & $36,6 \pm 37,5$ & $36 \pm 37$ & $-2,560$ & 0,010 \\
\hline Pernafasan & 19,1 & 18,6 & $18 \pm 21$ & $18 \pm 20$ & $-2,325$ & 0,020 \\
\hline $\begin{array}{l}\text { Lama Persalinan } \\
\text { Kala III }\end{array}$ & 19,3 & 17,2 & $15 \pm 28$ & $15 \pm 20$ & $-2,581$ & 0,010 \\
\hline $\begin{array}{l}\text { Perdarahan kala } \\
\text { III }\end{array}$ & 318,6 & 313,6 & $310 \pm 325$ & $300 \pm 320$ & $-2,823$ & 0,005 \\
\hline
\end{tabular}

Tabel 4. Hasil Pengujian Perubahan Tekanan Sistole,Diastole,Nadi,Suhu,Pernafasan,Lama Persalinan Kala IV Pada Kelompok Perlakuan Senam Hamil dan Kelompok Komunikasi Terapeutik

\begin{tabular}{lllcccc}
\hline \multirow{2}{*}{ Variabel } & \multicolumn{2}{c}{ Mean } & \multicolumn{2}{c}{ Min \pm Maks } & Z & p-value \\
\cline { 2 - 6 } & $\begin{array}{c}\text { Senam } \\
\text { Hamil }\end{array}$ & $\begin{array}{c}\text { Kom. } \\
\text { Tera } \\
\text { peutik }\end{array}$ & $\begin{array}{c}\text { Senam } \\
\text { Hamil }\end{array}$ & $\begin{array}{c}\text { Kom. } \\
\text { Tera } \\
\text { peutik }\end{array}$ & & \\
\hline Tekanan darah Sistole & 118,6 & 113,6 & $110 \pm 125$ & $100 \pm 120$ & $-2,823$ & 0,005 \\
\hline Tekanan darah Diastole & 79,2 & 70,9 & $70 \pm 85$ & $60 \pm 80$ & $-4,268$ & 0,000 \\
\hline Nadi & 85,2 & 82 & $84 \pm 86$ & $77 \pm 85$ & $-4,878$ & 0,000 \\
Suhu & 36,2 & 36 & $35,9 \pm 37$ & $35,9 \pm 36,5$ & $-3,356$ & 0,001 \\
\hline Pernafasan & 18,4 & 17,7 & $16 \pm 20$ & $17 \pm 19$ & $-2,591$ & 0,010 \\
Perdarahan kala IV & 87,6 & 78,9 & $78 \pm 98$ & $68 \pm 88$ & $-4,306$ & 0,000 \\
\hline
\end{tabular}

\section{PEMBAHASAN}

Pengukuran yang dilakukan adalah dengan melihat hasil sebelum perlakuan (pre test) dan setelah perlakuan (post test). Pengukuran dengan cara ini diperlukan untuk melihat seberapa besar pengaruh perlakuan, dalam hal 
Jurnal Care Vol .5, No.3,Tahun 2017

ini perlakuan komunikasi terapeutik dan senam hamil, terhadap proses persalinan kala I,II,III, dan IV. Pre test digunakan untuk melihat besaran nilai responden sebelum diberi perlakuan sedangkan post test digunakan untuk melihat seberapa besar nilai pengaruh komunikasi terapeutik dengan senam hamil terhadap proses persalinan kala I,II,III, dan IV.

Hasil perhitungan dengan uji paired t test dalam penelitian ini menunjukkan kelompok responden yang diberi perlakuan berupa komunikasi terapeutik dan senam hamil mengalami perbedaan yang spesifik. Kondisi ini mengindikasikan bahwa perlakuan komunikasi terapeutik dan senam hamil yang diberikan kepada ibu hamil mempunyai pengaruh terhadap proses persalinan kala I,II,III, dan IV. Menurut Stuart G.W dalam (Uripni dkk, 1998)) komunikasi terapeutik merupakan hubungan interpersonal antara bidan dengan pasien, dalam hubungan ini bidan dan pasien memperoleh pengalaman belajar bersama dalam rangka memperbaiki pengalaman emosional pasien. Sehingga ibu hamil yang diberi perlakuan komunikasi terapeutik lebih mempunyai pengaruh dibandingkan dengan senam hamil, karena dengan komunikasi terapeutik keadaan emosional pasien lebih terkontrol sehingga bidan bisa membantu jika pasien mengalami kesulitan pada saat proses persalinan. Purwanto dalam Mukhripah (2008) menyatakan bahwa komunikasi terapeutik bertujuan untuk membantu pasien dalam memperjelas dan mengurangi beban perasaan dan pikiran serta dapat mengambil tindakan untuk mengubah situasi yang ada agar pasien percaya pada hal yang diperlukan ; mengurangi keraguan, membantu dalam hal mengambil tindakan yang efektif dan mempertahankan kekuatan egonya ; mempengaruhi orang lain, lingkungan fisik dan dirinya sendiri.

Senam hamil adalah latihan gerak tertentu untuk melatih otot-otot dinding perut untuk mempersiapkan ibu hamil pada persalinan yang aman, cepat, dan spontan ( Depkes, 2015). Menurut Manuaba dan Chandranita(2009) bahwa senam hamil memudahkan ibu untuk melakukan tugas persalinan dengan kekuatan dan kepercayaan diri sendri dibawah bimbingan penolong pada persalinan normal (fisiologis). Sehingga ibu hamil yang diberi perlakuan senam hamil hanya mampu mempersiapkan persalinan secara fisik yaitu kekuatan pada saat akan bersalin. Manfaat senam hamil ialah memperbaiki sirkulasi darah, menggurangi bengkak teutama kaki, meningkatkan keseimbangan otot-otot, mengurangi kejang 
Jurnal Care Vol .5, No.3,Tahun 2017

kaki/kram, menguatkan otot-otot perut, mempercepat penyembuhan setelah kehamilan, memperbaiki posisi janin (Hani $\mathrm{dkk}, 2010)$.

Berdasarkan hasil tersebut dapat ditarik kesimpulan bahwa memberi perlakuan komunikasi terapeutik terhadap ibu hamil dapat diterapkan di lingkungan pelayanan kesehatan. Kelancaran proses persalinan yang diperoleh dalam penelitian ini, baik yang disampaikan dengan komunikasi terapeutik maupun senam hamil memberikan arti bahwa kedua metode ini sama-sama mempengaruhi proses persalinan. Namun demikian, kelancaran proses persalinan pada kala I,II,III, dan IV dengan menggunakan perlakuan komunikasi terapeutik mempunyai kemampuan meningkatkan kelancaran proses persalinan kala I,II,III, dan IV lebih tinggi dibandingkan dengan senam hamil.

\section{KESIMPULAN}

Komunikasi terapeutik lebih dominan terhadap kemudahan atau kelancaran pada proses persalinan kala I,II,III,dan IV. Perubahan ini terjadi baik terhadap tekanan darah systole, diastole, nadi, suhu, pernafasan, perdarahan dan lama persalinan.
Direkomendasikan untuk menggunakan pendekatan komunikasi terapeutik pada ibu hamil atau ibu yang akan bersalin sehingga nantinya dengan menggunakan pendekatan komunikasi terapeutik dapat mempermudah atau memperlancar pada saat proses persalinan pada kala I,II,III dan IV.

\section{REFERENSI}

Depkes RI. (2008). Asuban Persalinan Normal. Jakarta: JNPK-KR

Depkes RI. (2015). Buku Kesehatan Ibu Dan Anak. Jakarta: Kementerian Kesehatan dan JICA

Hani, dkk. (2010). Asuban Kebidanan pada Kehamilan Fisiologis. Jakarta: Salemba Medika

Hidayat,A.,Sujiatini. (2010). Asuban Kebidanan Persalinan. Yogyakarta: Nuha Medika

Manuaba., Chandranita,I. (2009). Pengawasan Antenatal. Jakarta: EGC

Mukhripah, D. (2008). Komunikasi Terapeutik dalam Praktik Keprawatan. Bandung: Refika Aditama

Uripni,C., dkk. (2003). Komunikasi Kebidanan. Jakarta: Penerbit Buku Kedokteran 